temporary erosion in his research area is not valid, but is the product of contemporary deposition in a region of aggrading ground ice. His quest for an explanation for geologically discordant plateaux takes him to the "peritropical" zones of contemporary etchplain development which he sees as the process for the formation of extensive, low-relief plains. To most of the British geomorphologists interested in cold-climate processes his descriptions of weathering and wash processes in humid tropical regions give a most illuminating explanation for our much-abused and little-understood erosion surfaces.

In many ways, Büdel's views must make geomorphologists in the English-speaking world reassess the results of their singlecase, analytical studies. For instance, it is interesting to consider if the approach taken by the contributors to Derbyshire's Geomorphology and Climate - published in 1976 (by Wiley) one year before Climatic Geomorphology appeared in Germany gives a greater insight into how landforms and landscapes develop, if it achieves less or if it says the same thing in different ways. For what it is worth, my views are that the recent efforts of English-speaking geomorphologists have contributed much that is of significance to their subject, and that much of Büdel's criticism is unjustified. Equally, however, I believe that without the wisdom shown by Büdel's synthesis many of the individual analytical studies will be wasted.

J. Rose is a Lecturer in Geography at Birkbeck College, University of London.

\title{
Bonding chemistry unravelled
}

\section{B.F.G. Johnson}

\section{Multiple Bonds Between Metal Atoms. By F. Albert Cotton and Richard A. Walton. Pp.466. ISBN 0-471-04686-8. (Wiley: 1982.) $\$ 63.20, £ 39.50$.}

I ADMIRE few chemists as much as F.A. Cotton. He has had a long and successful career and became one of the few inorganic chemists to achieve international prominence, both through the excellence of his research and because he can always be counted on to provide a clear description and cogent explanation of his chemistry. He is a highly skilled author and together with Dick Walton has written a classic book on multiple bonds between metal atoms. This (in my opinion) is Cotton's favourite topic and it shows.

The book examines the fundamental chemistry of compounds containing metalmetal bonds with bond orders greater than one. The study of such compounds has contributed much to modern inorganic chemistry. Unravelling the bonding problems provided by their structures has provided a wonderful stimulus to researchers, from which a totally new and exciting branch of chemistry has emerged.

"Introduction and Survey", the first of the eight chapters in the book, provides a fascinating insight into the genesis of this area of research and how it continues to progress. Apart from this and a further chapter devoted to physical, spectroscopic and theoretical results, the book deals with the formation of multiple bonds found between metal atoms (rhenium, molybdenum, tungsten and rhodium), and with their synthesis, structure and chemistry. Each chapter has been carefully sub-divided into small packages of information, thereby providing a concise and easily followed account. By so doing those of us concerned with compiling a succinct lecture course or simply locating information relevant to our own research will have few problems. There is a wealth of good diagrams and tables, the literature survey is first class and the overall standard of production is excellent.

Cotton and Walton have provided a clear insight into the chemistry and importance of multiple metal-metal bonds. They have written a valuable and entertaining mix of chemistry, reminiscence and opinion, and have thereby given us an enjoyable, readable book which is a must for all practising inorganic chemists.

B.F.G. Johnson is Reader in Inorganic Chemistry at the University of Cambridge.

\section{Everyman's guide to molecular cloning}

\section{Noreen E. Murray}

Molecular Cloning: A Laboratory Manual. By T. Maniatis, E.F. Fritsch and J. Sambrook. Pp.545. Pbk ISBN 0-87969136-0. (Cold Spring Harbor Laboratory: 1982.) $\$ 40$ (US), $\$ 48$ (elsewhere).

For ten years the Cold Spring Harbor publication Experiments in Molecular Genetics by J.H. Miller has been a popular and reliable reference book for those working with Escherichia coli and its phages. I had anticipated that the laboratory manual Molecular Cloning would serve a similar role for those using E. coli as host and its plasmids and phages as vectors for the cloning and analysis of DNA. The long awaited manual is now available and I expect few readers to be disappointed.

The manual emphasizes both the biological systems and biochemical tools available. Each topic is introduced clearly, though concisely, taking care to equip the reader with some understanding of the systems and techniques he may use. Quite elementary information is included and a motivated, and perhaps green-fingered, novice should be able to start from simple experiments and rise to the more sophisticated technology, given, of course, the availability of a battery of good enzymes. Even here advice is offered about the careful use and preservation of enzymes. Although the volume is a laboratory manual it is not lacking in basic theoretical information, is well supplied with references and is amply provided with clear illustrations.

The authors have covered the predicted range of topics including vector-host systems, gel electrophoresis, isolation of mRNA, cDNA cloning, the construction of gene libraries and the detection and analysis of recombinant molecules. The information is supplemented with useful appendices full of recipes and simple biochemical methods. In some areas the manual is up to the minute, particularly in its presentation of a recombination method for screening bacteriophage lambda libraries for specific DNA sequences. In contrast it denies the usefulness of bacteriophage $\lambda$ as an efficient means of cloning cDNA despite contrary documentation in the literature early in 1981 .

One criticism that I would make of this otherwise excellent manual, a criticism that possibly reflects the pressures of a fastmoving field, is the presence of more errors than one usually associates with Cold Spring Harbor publications. Thus a list of around $20 \mathrm{E}$.coli strains includes at least five mistakes. Some of these - for example, supF where it should be supE are likely to confuse the beginner who will assume that he himsclf, and not the manual, is in error. In similar vein, $\lambda$ sep6lac5 is stated to be exceptional in having the red and gam genes in its right arm; in fact, it is not exceptional and furthermore, since it is $\mathrm{gam}^{+}$and $\mathrm{red}^{-}$(not red ${ }^{+}$) it may be propagated on a rec $A$ - host in the absence of both phage and host recombination systems.

Despite such blemishes I strongly recommend this manual. Those working in the area of molecular cloning, or contemplating doing so, may have received their copy already; others should put their name on the waiting list.

Noreen Murray is Reader in the Department of Molecular Biology at the University of Edinburgh.

Nature publishes an annual review of new journals. This year's New Journals Review appeared in the issue of 7 October. 